ARTIGO

\title{
ESCOLAS DO CAMPO E INFRAESTRUTURA: ASPECTOS LEGAIS, PRECARIZAÇÃO E FECHAMENTO
}

\author{
FRANCISCA MARLI RODRIGUES DE ANDRADE ${ }^{1}$ \\ ORCID: https://orcid.org/0000-0001-6450-5911
}

MARCELA PEREIRA MENDES RODRIGUES ${ }^{2}$

ORCID: https://orcid.org/0000-0003-3104-9555

\begin{abstract}
RESUMO: A efetivação do direito à educação do campo para as comunidades campesinas compreende grandes desafios, os quais perpassam desde os aspectos pedagógicos até a infraestrutura. Em função desses desafios, esta pesquisa tem por objetivo apresentar a realidade de três escolas do campo localizadas no Noroeste Fluminense, estado do Rio de Janeiro. Concretamente, analisamos as condições infraestruturais dessas escolas, com base em três categorias analíticas: infraestrutura arquitetônica; infraestrutura básica; e equipamentos. Metodologicamente, a pesquisa está pautada no enfoque qualitativo de caráter exploratório. O processo de coleta de dados aconteceu no período entre 2015 e 2019, por meio da observação-participante, em decorrência das vivências pedagógicas realizadas nas três escolas. Os dados coletados a partir dessas vivências foram sistematizados em um diário de campo e, posteriormente, analisados com base nas políticas públicas de educação. Enquanto principais resultados da pesquisa, evidenciamos a negligência do poder público no cumprimento dos padrões mínimos de infraestrutura das escolas. $\mathrm{Na}$ sequência, tal poder utiliza o argumento da precarização, enquanto justificativa, para colocar em prática uma política criminosa de fechamento de escolas do campo. Essa política não é um fenômeno isolado do contexto estudado, reflete, portanto, a realidade nacional.
\end{abstract}

Palavras-chave: Escolas do campo; infraestrutura; precarização; fechamento.

\section{RURAL AREA SCHOOLS AND INFRASTRUCTURE: LEGAL ASPECTS, PRECARIOUSNESS AND CLOSURE}

\begin{abstract}
The enforcement of the right to Rural area Education for peasant communities comprises major challenges, which go through the pedagogical aspects of the infrastructure. Due to these challenges, the basic aim of this article is to present the reality of three rural schools located in Northwestern, of the State of Rio de Janeiro - Brazil. In practical terms, we analyzed the infrastructural conditions of these schools based on three analytical categories: architectural infrastructure; basic infrastructure; and equipment. The data collection process took place between 2015 and 2019, through participant observation as part of the pedagogical experiences carried out in the three schools. As the
\end{abstract}

\footnotetext{
${ }^{1}$ Universidade Federal Fluminense (UFF). Santo Antonio de Pádua, RJ, Brasil. <marli_andrade@id.uff.br>

${ }^{2}$ Universidade Federal Fluminense (UFF). Santo Antonio de Pádua, RJ, Brasil. <marcelamendes@id.uff.br>
} 
main results, we highlight the gross negligence of the public authorities on compliance with the minimum infrastructure standards of schools. Subsequently, such power uses the precariousness argument as their excuse to put into practice a criminal policy of rural schools closure. This policy is not an isolated phenomenon from the studied context. It therefore reflects the national reality.

Keywords: Rural area schools; infrastructure; precariousness; closure.

\section{ESCUELAS EN CONTEXTOS RURALES E INFRAESTRUCTURA: ASPECTOS LEGALES, PRECARIZACIÓN Y CIERRE}

RESUMEN: La concretización del derecho a la educación en contextos rural para las comunidades campesinas comprende desafíos importantes, los cuales pasan desde los aspectos pedagógicos hasta la infraestructura. Debido a estos desafíos, esta investigación tiene como objetivo presentar la realidad de tres escuelas rurales ubicadas en el Noroeste del estado de Rio de Janeiro - Brasil. Específicamente, analizar las condiciones de la infraestructura de estas escuelas, en base a tres categorías analíticas: infraestructura arquitectónica; infraestructura básica; y equipos electrónicos. Metodológicamente, la investigación se basa en un enfoque cualitativo exploratorio. El proceso de recopilación de los datos tuvo lugar entre los años de 2015 y 2019, a través de la observación participante, como resultado de las experiencias pedagógicas llevadas a cabo en las tres escuelas. Los datos recopilados a partir de las experiencias fueron sistematizados en un diario de campo y, por lo tanto, analizados con base en las políticas públicas de educación. En cuanto a los resultados principales de la investigación, se destaca la negligencia de las autoridades públicas al cumplir con los estándares mínimos de infraestructura de las escuelas. Posteriormente, dichas autoridades utilizan el argumento de la precariedad, como justificación, para poner en práctica una política criminal de cierre de escuelas rurales. Esta política no es un fenómeno aislado del contexto estudiado, refleja, por lo tanto, la realidad nacional.

Palabras clave: Escuelas en contextos rurales; infraestructura; precariedad; cierre. 


\section{INTRODUÇÃO}

A Educação do Campo nasce a partir das lutas e reivindicações sócio-históricas dos movimentos sociais, voltadas aos interesses das populações campesinas em seu sentido mais amplo; ou seja, "questões do trabalho, da cultura, do conhecimento e das lutas sociais dos camponeses e ao embate (de classe) entre projetos de campo e entre lógicas de agricultura", entre outros (CALDART, 2012, p. 257). Entre tais interesses, destacamos o conceito de escola do campo, estabelecido na Política de Educação do Campo (Procampo) - Decreto no 7.352 de 4 de novembro de 2010; isto é, "aquela situada em área rural, conforme definida pela Fundação Instituto Brasileiro de Geografia e Estatística IBGE, ou aquela situada em área urbana, desde que atenda predominantemente a populações do campo" (BRASIL, 2010). Dessa forma, a proposta pedagógica construída nas escolas do campo reflete as especificidades das comunidades locais nas quais estão inseridas, uma vez que as populações do campo são múltiplas e diversas, constituem suas identidades de acordo com as suas próprias realidades. Sobre este aspecto, as Diretrizes Operacionais para a Educação Básica nas Escolas do Campo ressaltam que:

Art. 2 - Parágrafo único. A identidade da escola do campo é definida pela sua vinculação às questões inerentes à sua realidade ancorando-se na temporalidade e saberes próprios dos estudantes, na memória coletiva que sinaliza futuros, na rede de ciência e tecnologia disponível na sociedade e nos movimentos sociais em defesa de projetos que associem as soluções exigidas por essas questões à qualidade social da vida coletiva do País (BRASIL, 2002, p. 1).

Historicamente, as escolas do campo compreendem grandes desafios que perpassam pela infraestrutura e falta de recursos como: alimentação, transporte escolar e materiais didáticos específicos, entre outros (LUTHER; GERHARDT, 2018). Logo, as condições infraestruturais precárias das escolas do campo acentuam alguns dos empecilhos relacionados à universalização da educação e, portanto, as tensões e os interesses do capital em territórios da América Latina. Tais interesses atuam de forma articulada nas mais altas esferas do poder, para manutenção de uma concepção de escola rural precarizada, "profundamente distanciada da realidade do trabalho e da vida dos agricultores” (RIBEIRO, 2013, p. 176). Nesse sentido, a precarização, viabilizada pelo ideal de escola rural, contribui para a construção de representações preconceituosas das escolas do campo como atrasadas e/ou inferiores as da cidade, com sérias implicações na autoestima cognitiva e moral das populações campesinas, afro-brasileiras e indígenas (BANIWA, 2019). Para confrontar essas representações, resgatamos o efetivo significado das escolas do campo; ou seja, aquela que "se enraíza no processo histórico da luta de classe trabalhadora pela superação do sistema do capital" (MOLINA; SÁ, 2012, p. 325).

Pensar as escolas do campo significa inseri-las em "uma concepção que emerge das contradições da luta social e das práticas de educação dos trabalhadores do e no campo" (MOLINA; SÁ, 2012, p. 324). Pois, as escolas do campo exercem o papel de proporcionar um projeto educativo e de sociedade que "efetivamente desenvolva a promoção humana, de forma emancipatória e libertadora, que define o ponto de partida da prática pedagógica o homem em sua complexidade histórico-cultural, com suas contradições, ambiguidades e possibilidades" (COELHO, 2011, p. 137). Por essas e outras razões, o impasse para a institucionalização, mais ampla, da Educação do Campo se materializa com o desmonte de políticas públicas voltadas para o campo e o contínuo fechamento de escolas. De acordo com um relatório apresentado pela UFSCAR ${ }^{3}$, "das mais de 100 mil escolas rurais que existiam em 2002 no Brasil, 17 mil foram fechadas, isso representou, nas regiões Sul e Centro-Oeste, uma redução de mais de (39\%), seguidas pela região Nordeste (22,5\%), Sudeste (20\%) e Norte $(14,4 \%)$ " (CASSIN; BEZERRA, 2017).

Os dados sobre fechamentos de escolas do campo, apresentados por Cassin e Bezerra (2017), sinalizam que existem tentativas, com apoio de algumas esferas governamentais, de negação do direito à educação, enquanto estratégia de esvaziamento do campo para atender as demandas

\footnotetext{
${ }^{3}$ Para mais informações, consulte: <http://www.fai.ufscar.br/noticia/numero-de-escolas-no-campo-diminui-drasticamenteno-brasil.html>.
} 
requeridas pela atual versão do capital (SOARES NETO et al., 2013; ANDRADE et al., 2019a; NEVES et al., 2019). Entre tais demandas encontra-se a concentração de terras, a expansão do agronegócio e a apropriação voraz da natureza (CALDART, 2012). Sobre esse aspecto, Acselrad (2014, p. 89) destaca que "sob o discurso do 'neo-desenvolvimentismo', o mercado de terras no Brasil tem desempenhado papel estratégico na reestruturação do capitalismo agrário mundial”. Para o autor, "as corporações internacionalizadas em geral, nesse terreno encontram-se em expansão as fronteiras da exploração mineral, dos recursos energéticos e da água" (ACSELRAD, 2014, p. 89).

O fechamento sistemático de escolas do campo releva-se como uma contraditória nacional, uma vez que o direito à Educação do Campo é garantido por lei - tanto constitucionalmente, quanto pela Política de Educação do Campo e pelo Programa Nacional de Educação do Campo (Procampo). A contraditória persiste quando o acesso das populações do campo a uma educação diferenciada é negado pela falta e/ou precarização das escolas. Para uma melhor compreensão dessas questões, resgatamos o relatório elaborado pelo Instituto Nacional de Estudos e Pesquisas Educacionais Anísio Teixeira (INEP) ${ }^{4}$, sobre o panorama da Educação do Campo no Brasil. Esse documento, enquanto diagnóstico, sinaliza algumas questões, entre elas "a insuficiência e a precariedade das instalações físicas da maioria das escolas", como um dos principais obstáculos ao desenvolvimento pleno da Educação do Campo (INEP, 2007). O relatório elaborado pelo INEP aponta, também, que:

A precariedade na infraestrutura afeta, no caso da inexistência de energia elétrica, aproximadamente 766 mil alunos do ensino fundamental. A impossibilidade de ter acesso a uma biblioteca contribui de forma negativa para o aprendizado de cerca de 4,8 milhões. As tecnologias educacionais não chegaram à expressiva maioria das escolas da área rural, privando os alunos de oportunidades de aprendizagem mediante o uso de televisão, vídeo e Internet (INEP, 2007, p. 30).

Em relação aos aspectos levantados pelo INEP, concordamos com Soares Neto e colaboradores (2013, p. 377) que a fragilidade, no tocante a infraestrutura disponibilizada pelas esferas públicas locais às escolas do campo, compromete a qualidade do ensino, uma vez que "o processo de ensino-aprendizagem é complexo e exige a interação de diversos fatores para ser realizado de forma adequada". Logo, esses fatores vão "desde um corpo docente qualificado até condições de infraestrutura escolar favorável, o que inclui materiais didáticos, equipamentos, e estruturas físicas apropriadas" (SOARES NETO et al., 2013, p. 377). Por esse motivo, persiste a preocupação de Luther e Gerhardt (2018, p. 300) em relação à ausência de critérios voltados aos "espaços escolares 'sem estrutura mínima' para a aprendizagem”, já que essa ausência é utilizada como argumento para fechar e/ou nuclearizar as escolas do campo. Essa questão também foi discutida nas pesquisas de Rodrigues e colaboradores (2017), quando ressaltam que o processo de fechamento de escolas do campo, em especial nas zonas rurais de municípios paraibanos, é estudado de modo a entender as práticas de nucleação e/ou ordenamento dessas escolas.

A ausência do Estado em garantir as condições estruturais para o funcionamento das escolas do campo, de acordo com Rodrigues e colaboradores (2017, p. 709), faz com que as/os estudantes que vivem em "comunidades que apresentam baixo número de matrículas ou caracterizadas como isoladas, devido à precária infraestrutura" sejam alocados em "escolas de comunidades vizinhas melhores aparelhadas" (RODRIGUES et al., 2017, p. 709). Com isso, o fechamento de escolas tem provocado queda no número de matrículas na zona rural, fazendo com que muitos estudantes migrem para as cidades ou simplesmente abandonem as escolas (INEP, 2007; SOARES-NETO et al., 2013). Por um lado, "muitos estados vêm reorganizando suas respectivas redes escolares em um provável processo de nucleação escolar que centralizaria as escolas em áreas urbanas, criando uma concentração educacional urbana" (RODRIGUES et al., 2017, p. 709). Por outro, "algumas justificativas para o fechamento vêm sendo divulgadas há décadas: problemas de infraestrutura, qualificação profissional insuficiente e baixo número de jovens vivendo em localização fora da cidade" (LUTHER;

\footnotetext{
4 Para ter acesso ao relatório do INEP, http://inep.gov.br/documents/186968/484154/Panorama+da+Educa\%C3\%A7\%C3\%A3o+do+Campo/5b9c2ed7-208b$48 \mathrm{ff}-\mathrm{a} 803-\mathrm{cd} 3851 \mathrm{c} 5 \mathrm{c} 6 \mathrm{c} 9$ ? version $=1.2$
} 
GERHARDT, 2018, p. 304). Todos esses elementos são utilizados para justificar e potencializar os processos de nucleação e fechamento de escolas.

\section{VIVÊNCIAS NO CAMPO: A OBSERVAÇÃO-PARTICIPANTE COMO METODOLOGIA DE PESQUISA}

A pesquisa teve como base o enfoque qualitativo, de caráter exploratório. Enquanto estudo exploratório volta-se aos "os aspectos qualitativos das informações à possibilidade de quantificá-los posteriormente. Esta associação realiza-se em nível de complementaridade, possibilitando ampliar a compreensão do fenômeno em estudo" (PIOVESAN; TEMPORINI, 1995, p. 322). O trabalho empírico aconteceu vinculado à Licenciatura Interdisciplinar em Educação do Campo da Universidade Federal Fluminense (UFF), no prospecto do Tempo Comunidade (TC) ${ }^{5}$. Para melhores esclarecimentos, o Tempo Comunidade apresenta-se como um dos espaços-tempos de aprendizagem da Pedagogia da Alternância, por meio da qual se busca articular teoria e prática numa práxis (RIBEIRO, 2013). Nesse sentido, o Tempo Comunidade corresponde a 30\% do currículo educativo e, portanto, possibilita às/aos estudantes vivências reais de produção de experiências empíricas, articuladas e integradas às comunidades campesinas, indígenas e quilombolas (RIBEIRO, 2013; ANDRADE et al., 2019b). Desse modo, o Tempo Comunidade na referida licenciatura...

Potencializa conhecimentos, aprendizagens e habilidades pensadas em espaços sociais historicamente marginalizados pela lógica da modernidade do saber/poder, tais como: assentamentos, quilombos, sindicatos de trabalhadores rurais, movimentos sociais, escolas do campo e a própria vida no campo. Revela-se, desse modo, como um laboratório de experiências sociais, políticas e ambientais que desafiam e desestabilizam, de diferentes formas, o projeto de colonialidade/modernidade que impera em território nacional (ANDRADE et al., 2019b, p. 25-26).

O Tempo Comunidade tem como finalidade proporcionar aprendizagens pautadas na experiência social, na qual a produção de conhecimentos é mediada pela observação e "participação ativa nos processos sociais, políticos, econômicos e ambientais da comunidade" (ANDRADE et al., 2019a). Na consolidação do Tempo Comunidade, nossa pesquisa tem como objetivo apresentar a realidade de três escolas do campo, localizadas na cidade de Santo Antônio de Pádua, são elas: Escola Alice do Amaral Peixoto, Escola João Neves Brum e Escola Anacleto Eccard Júnior, sendo que as duas últimas foram fechadas no ano de 2017, respectivamente. Nossas vivências nessas escolas se iniciaram durante o semestre letivo 2015.2, do curso de Licenciatura Interdisciplinar em Educação do Campo da UFF. Todas as três escolas funcionavam/funciona em período matutino e ofereciam/oferece à comunidade as modalidades de Educação Infantil: Pré-Escola (4 A 5 anos) e Ensino Fundamental no formato de classes multisseriadas. As três escolas tinham/tem como entidade mantenedora a Secretaria Municipal de Educação da cidade de Santo Antônio de Pádua, localizada na região Noroeste do estado do Rio de Janeiro - a 260 km de distância da capital.

\footnotetext{
${ }^{5}$ Melhores informações podem ser consultadas no artigo "Educação do Campo em giro decolonial: a experiência do Tempo Comunidade na Universidade Federal Fluminense (UFF)", disponível em: https://sistemas.uft.edu.br/periodicos/index.php/campo/article/view/7178
} 
Figura 1 - Localização da cidade de Santo Antônio de Pádua no mapa do Estado do Rio de Janeiro

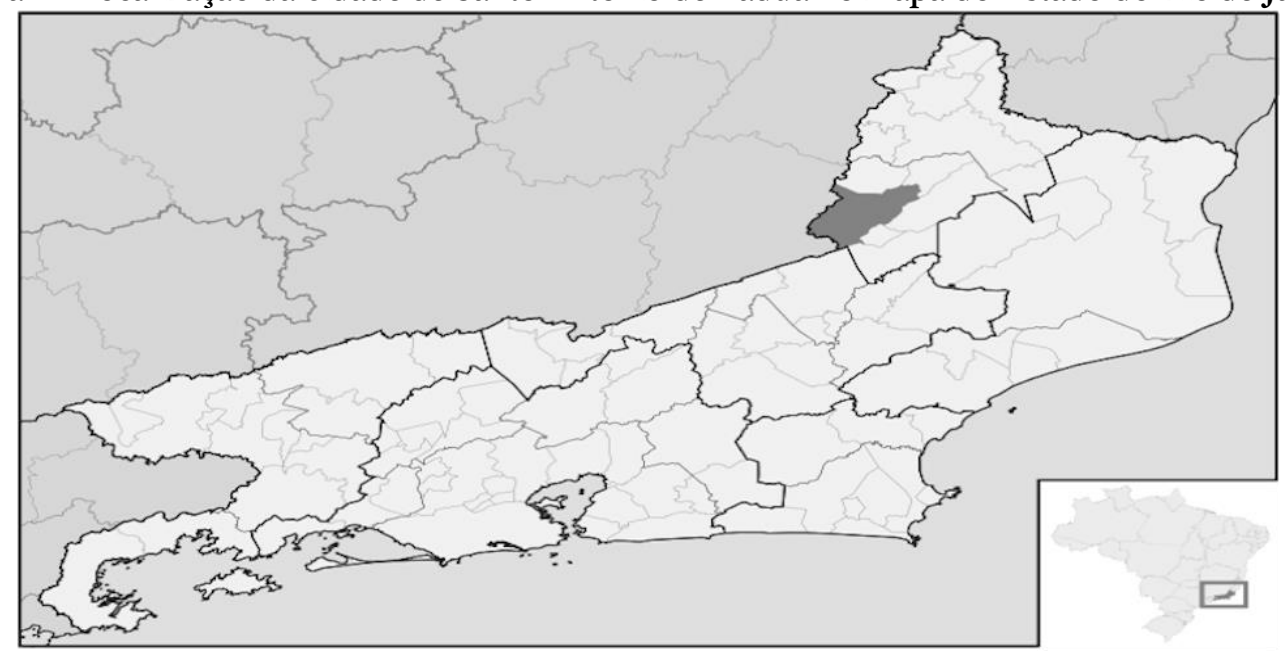

Fonte: Map of Rio de Janeiro ${ }^{6}$.

A referida pesquisa surge a partir da necessidade de compreender as relações e contradições que, entre o urbano e o rural, permeiam o território do interior do Noroeste Fluminense - Santo Antônio de Pádua, com uma população de 40.589 habitantes (IBGE, 2010). Concretamente, as dinâmicas das instituições educativas de uma cidade com um expressivo número de pessoas que vivem em áreas rurais, quase $10 \%$ de sua população (IBGE, 2010) ${ }^{7}$. Com esses elementos, analisar as dinâmicas sociais, sob a ótica da Educação do Campo, nos remete a um vínculo obrigatório com as lutas sociais que vêm sendo travadas na região, sobretudo aquelas voltadas aos direitos educativos diferenciados (NEVES et al., 2019). Para isto, adotamos enquanto metodologia de pesquisa a observação-participante, tendo em vista que este enfoque pode ser considerado como parte substancial do trabalho de campo nos estudos qualitativos. Entendemos como observação participante:

[...] um processo pelo qual um pesquisador se coloca como observador de uma situação social com a finalidade de realizar uma investigação científica. O observador, no caso, fica em relação direta com seus interlocutores no espaço social da pesquisa, na medida do possível, participando da vida social deles, no seu cenário cultural, mas com a finalidade de compreender o contexto da pesquisa. Por isso, o observador faz parte do contexto sob sua observação e, sem dúvida, modifica esse contexto, pois interfere nele, assim como é modificado pessoalmente (MINAYO, 2013, p. 70).

Para além disso, a aproximação com as três escolas foi se consolidando gradualmente à medida que o convívio com a comunidade local suscitava questões relevantes. Na tentativa de evitar o fechamento da Escola Alice do Amaral Peixoto "a comunidade articulou, juntamente com o curso de Licenciatura Interdisciplinar em Educação do Campo da UFF, estratégias que tinham como finalidade fortalecer sua luta e ampliar sua voz e, portanto, as possibilidades de diálogos com a rede municipal de Educação" (NEVES et al., 2019, p. 132). A articulação social aconteceu/acontece enquanto estratégia para fortalecer o movimento de resistência, a partir da construção da memória social da comunidade. Nesse sentido, o projeto político da Educação do Campo nos oferece as ferramentas analíticas para compreendermos "a noção de memória e antecipação que nos remete a um novo olhar para a comunidade" (NEVES et al., 2019, p. 134).

A noção de memória e antecipação coloca-nos em luta pela valorização da comunidade, dos sujeitos e dos saberes locais, uma vez que "a radicalidade política, cultural e educativa, que vem dos próprios movimentos sociais e dos seus processos de formação como militantes-educadores", viabiliza essa possibilidade (ARROYO, 2012, p. 362). Logo, a observação-participante torna possível a realização de vivências e experiências concretas, as quais nos ajudam a desvelar certas contradições entre as políticas públicas educacionais para o campo e as experiências vivenciadas cotidianamente pela comunidade local. Para Whyte (2005, p. 283), "quando o pesquisador está instalado numa universidade,

${ }^{6}$ Para ter acesso ao site, consulte: https://pt.map-of-rio-de-janeiro.com/regiões-mapas/santo-antônio-de-pádua-mapa

${ }^{7}$ Para mais informações, consulte: https://cidades.ibge.gov.br/brasil/rj/santo-antonio-de-padua/panorama 
indo ao campo apenas por poucas horas de cada vez, pode manter sua vida social separada da atividade de campo. Lidar com seus diferentes papéis não é tão complicado". Contudo, conforme o autor destaca, "se viver por um longo período na comunidade que é o seu objeto de estudo, sua vida pessoal estará inextricavelmente associada à sua pesquisa" (WHYTE, 2005, p. 283).

A observação-participante mostra-se como um método interessante para pesquisadoras(es) e educadoras(es) na área da Educação do Campo, uma vez que "o pesquisador que se dispõe a realizar uma pesquisa etnográfica assume uma visão holística com vistas a obter a descrição mais ampla possível do grupo pesquisado" (GIL, 2010, p. 127). Com base nesses conceitos, a construção da pesquisa foi sistematizada por meio da elaboração de um roteiro dos aspectos a serem observados. Esse roteiro foi validado a partir de um constructo para o qual resgatamos os principais documentos, diretrizes e bases nacionais voltadas à Educação do Campo. Portanto, o trabalho empírico de coleta de dados aconteceu no período entre 2015 e 2019, durante as vivências de Tempo Comunidade da Licenciatura Interdisciplinar em Educação do Campo da UFF, nas três escolas já citadas. Enquanto possibilidade de análise, voltamos nossa atenção à infraestrutura das três escolas enquanto categoria macro, subdividida em três aspectos: a) infraestrutura arquitetônica b) serviços de infraestrutura básica c) equipamentos necessários ao funcionamento das escolas do campo.

As informações da pesquisa foram registradas no diário de campo e após sistematização das mesmas, coube-nos analisá-las e interpretá-las com base em uma fundamentação teórica que envolve a Educação do Campo, em perspectiva interdisciplinar. Em nossas análises e interpretações, nossa maior preocupação consistiu em apresentar a realidade de três escolas do campo no Noroeste Fluminense, desde um entendimento de escola do campo que promove formação humana e emancipação (RIBEIRO, 2013). O significado de escola do campo, defendido nesta pesquisa, evoca temas que aparecem no centro das disputas políticas e econômicas atuais, uma vez que assumem o "desafio de conceber e desenvolver uma formação contra-hegemônica, ou seja, de formular e executar um projeto de educação integrado a um projeto político de transformação social liderado pela classe trabalhadora" (MOLINIA; SÁ, 2012, p. 327). Essa transformação "combina luta pela terra, pela Reforma Agrária, pelo direito ao trabalho, à cultura, à soberania alimentar, ao território" (CALDART, 2012, p. 263).

\section{INFRAESTRUTURA DAS ESCOLAS DO CAMPO: UMA ANÁLISE COM BASE NOS PARÂMETROS LEGAIS}

As questões estruturais das escolas apresentam-se como um elemento importante na pauta da qualidade educativa. Há mais de duas décadas, o Ministério da Educação (MEC) estabeleceu os Parâmetros Nacionais de Infraestrutura para as Instituições de Educação Infantil, visando "O funcionamento adequado das instituições [...] públicas e privadas" (BRASIL, 2006, p. 37). Por sua vez, o Decreto ${ }^{\circ}$ 7.352, de 4 de novembro de $2010^{8}$ - dispõe sobre a Política de Educação do Campo e o Programa Nacional de Educação na Reforma Agrária (PRONERA) - também apresentou alguns aspectos relacionados à infraestrutura das escolas do campo; isto é, "caberá à União criar e implementar mecanismos que garantam a manutenção e o desenvolvimento da educação do campo nas políticas públicas educacionais" (BRASIL, 2010). Para além desses regulamentos, os Parâmetros Nacionais de Infraestrutura destacam as condições de infraestrutura básica, imprescindível a qualquer escola que contemple o primeiro segmento de educação escolar, seja no campo ou nos centros urbanos:

a) espaço interno, com iluminação, insolação, ventilação, visão para o espaço externo, rede elétrica e segurança, água potável, esgotamento sanitário; b) instalações sanitárias e para a higiene pessoal das crianças; c) instalações para preparo e/ou serviços de alimentação; d) ambiente interno e externo para o desenvolvimento das atividades, conforme as diretrizes curriculares e a metodologia da Educação Infantil, incluindo Padrões de Infraestrutura para Espaço Físico Destinado à Educação Infantil repouso, expressão livre, movimento e brinquedo; e) mobiliário,

\footnotetext{
8 Para mais informações, consulte: http://portal.mec.gov.br/docman/marco-2012-pdf/10199-8-decreto-7352-de4-denovembro-de-2010/file
} 
equipamentos e materiais pedagógicos; f) adequação às características das crianças especiais (BRASIL, 2006, p. 37-38).

Tomando como referência esses padrões mínimos atribuídos pelo MEC e pelo Decreto $\mathrm{n}^{\mathrm{o}}$ 7.352/2010, analisamos as condições de infraestrutura das seguintes escolas: Alice do Amaral Peixoto, Joao Neves Brum e Anacleto Eccard Júnior. O propósito dessa análise consiste em evidenciar uma questão histórica no âmbito da Educação do Campo; ou seja, a negligência das agências governamentais, em alguns casos, no que diz respeito aos padrões mínimos de infraestrutura básica das escolas do campo (RODRIGUES et al., 2017; LUTHER; GERHARDT, 2018). Posteriormente, nos propomos a refletir sobre como o não cumprimento desses padrões pode interferir na qualidade da educação e, por conseguinte, representar as estratégias de estrangulamento que, por meio da lógica de precarização, tentam justificar o fechamento de escolas e o esvaziamento do campo, para atender as demandas do capital. Para uma melhor compreensão da realidade das escolas do campo no Noroeste Fluminense, apresentamos um quadro comparativo das escolas do campo localizadas nos seis municípios da microrregião de Santo Antônio de Pádua.

Quadro 1. Comparativo das Escolas do Campo no Noroeste Fluminense - Microrregião de Santo Antônio de Pádua (2015 - 2020)

\begin{tabular}{|c|c|c|c|}
\hline Municípios & $\begin{array}{l}\text { Escolas do Campo } \\
\text { M unicipais e Estaduais }\end{array}$ & $\begin{array}{l}\text { Escolas.inf.br } \\
(2015)\end{array}$ & $\begin{array}{l}\text { IN EP - I deb } \\
(2020)\end{array}$ \\
\hline \multirow{6}{*}{$\begin{array}{l}\text { Santo Antônio } \\
\text { de Pádua* }\end{array}$} & Ce Joao Maurício Brum & $\checkmark$ & $\checkmark$ \\
\hline & E M Joao Jazbik & $\checkmark$ & $\checkmark$ \\
\hline & Ce Pedro Batista da Silva & $\checkmark$ & $\checkmark$ \\
\hline & E M Alice do Amaral Peixoto\# & $\checkmark$ & $x$ \\
\hline & E M Anacleto Eccard Júnior & $\checkmark$ & $x$ \\
\hline & E M Joao Neves Brum & $\checkmark$ & $x$ \\
\hline \multirow{5}{*}{ Aperibé } & E M Antônio Ferreira da Luz & $\checkmark$ & $x$ \\
\hline & E M Prof. ${ }^{a}$ Maria Retto Rezende & $\checkmark$ & $x$ \\
\hline & E. M José Goncalves Brandao & $\checkmark$ & $x$ \\
\hline & E M Serra da Bolívia & $\checkmark$ & $x$ \\
\hline & E M Pito Aceso & $\checkmark$ & $x$ \\
\hline \multirow{4}{*}{ Cambuci } & E M Joao Brito Sanches & $\checkmark$ & $x$ \\
\hline & E M Pedro Jacinto Cabral & $\checkmark$ & $x$ \\
\hline & E M Bandarra & $\checkmark$ & $x$ \\
\hline & Ce Waldemiro Pita & $x$ & $\checkmark$ \\
\hline \multirow{4}{*}{ I taocara } & CE Jaime Queiroz de Souza & $\checkmark$ & $\checkmark$ \\
\hline & E M Prof. Genesio Maurício de Aguiar & $\checkmark$ & $x$ \\
\hline & E M Joaquim Soares Monteiro & $\checkmark$ & $x$ \\
\hline & E M Peri Peri & $\checkmark$ & $x$ \\
\hline \multirow{2}{*}{ Miracema } & E M Silvestre Mercante & $\checkmark$ & $\checkmark$ \\
\hline & E M Assad Joao & $\checkmark$ & $\checkmark$ \\
\hline \multirow{7}{*}{$\begin{array}{l}\text { São José de } \\
\text { Ubá }\end{array}$} & E M Prof. ${ }^{a}$ Clarita Maria & $\checkmark$ & $x$ \\
\hline & E M Maria de Ramos Azevedo & $\checkmark$ & $x$ \\
\hline & E M Afonso Batista Pinto & $\checkmark$ & $x$ \\
\hline & E M Ponte Preta & $\checkmark$ & $x$ \\
\hline & E M Antônio Gomes da Silva & $\checkmark$ & $x$ \\
\hline & E M Antônio Paula Silva & $\checkmark$ & $x$ \\
\hline & E M José Ivo Ribeiro da Silva & $\checkmark$ & $x$ \\
\hline
\end{tabular}

*As informações expostas no site Escolas.inf.br correspondem aos dados disponibilizados pela Secretaria Municipal de Santo Antônio de Pádua no ano de 2015.

\#Mesmo não constando no site do INEP - Ideb, esta escola continua em funcionamento. Fonte: Elaboração nossa. Dados da pesquisa (2015-2019), site Escolas.inf.br (2015) e INEP (2020). 
As informações da pesquisa indicam que as escolas do campo no Noroeste Fluminense, quando analisadas desde a ótica do Decreto $\mathrm{n}^{\circ} 7.352 / 2010$, encontram-se permeadas de contradições. Muitas dessas escolas, apesar de estarem localizas em zonas rurais e atenderem a um público majoritariamente do campo, têm a sua identidade negada quando não são reconhecidas pelas instâncias públicas enquanto escolas do campo. De acordo com os dados expostos no quadro 1, os municípios da microrregião Santo Antônio de Pádua contam com um número reduzido de escolas do campo, nas cidades de Aperibé e São José de Ubá os dados revelam a inexistência dessas escolas (INEP, 2020). Ao fazermos um comparativo das escolas do campo no período de 2015 a 2020, utilizando como base as informações expostas no site Escolas.inf.br (2015) ${ }^{9}$ e dados do INEP - Ideb (2020), verificamos a ausência - nessa segunda fonte - de 21 escolas de um total de 28 , o que representa $75 \%$ das escolas do campo da região. Essa evidência pode ter muitos significados, tais como: desativação, nucleação, fechamento e outros, os quais podem ser estudados futuramente. Os dados empíricos da pesquisa indicam que na cidade de Aperibé todas as escolas do campo foram fechadas antes do ano de 2015. Por sua vez, na cidade de Santo Antônio de Pádua as escolas Joao Neves Brum e Anacleto Eccard Júnior foram fechadas no ano de 2017, enquanto que a escola Alice do Amaral Peixoto, embora não conste nos dados oficiais do INEP, tem resistido às tentativas de fechamento.

\section{Infraestrutura arquitetônica: presenças e ausências nas escolas pesquisadas}

A estrutura física das escolas, de acordo com os dispositivos legais antes apresentados, deve ser projetada visando a acessibilidade, a funcionalidade; bem como, ser um espaço que busque contemplar a identidade da comunidade escolar e estimular as atividades de ensino e aprendizagem. Para Kowaltowski e colaboradores (2006, p. 10), a arquitetura escolar deve ser pensada de modo a "criar ambientes que priorizem os aspectos de conforto, funcionalidade, economia e estética, aplicando os conhecimentos artísticos, científicos, técnicos e de psicologia ambiental". A autora e seus colaboradores ressaltam que "o conforto ambiental, nos seus aspectos térmicos, acústicos, visuais e de funcionalidade, é um dos elementos da arquitetura que mais influencia o bem-estar" (KOWALTOWSKI et al., p. 2006, p. 10). Logo, a infraestrutura arquitetônica das escolas exerce um papel importante na qualidade da educação e, por isso, nesta parte da pesquisa, analisamos a infraestrutura das escolas do campo pesquisadas, em especial a sua estrutura física e/ou arquitetônica, de acordo com o quadro a seguir.

\footnotetext{
${ }^{9}$ Escolas.inf.br é um site de informações sobre escolas públicas e particulares no Brasil, o qual oferece informações sobre a localização, formas de contato, estrutura escolar, entre outras. As informações desse site foram utilizadas no ano de 2015 , para então mapearmos as escolas do campo da microrregião Santo Antônio de Pádua, no estado do Rio de Janeiro. Para maiores informações consultem http://www.escolas.inf.br
} 
Quadro 2. Infraestrutura arquitetônica das três escolas pesquisadas

\begin{tabular}{|c|c|c|c|}
\hline Aspectos observados & $\begin{array}{c}\text { Escola Alice } \\
\text { do Amaral } \\
\text { Peixoto }\end{array}$ & $\begin{array}{l}\text { Escola João } \\
\text { N eves Brum }\end{array}$ & $\begin{array}{c}\text { Escola } \\
\text { Anacleto } \\
\text { Eccard Junior }\end{array}$ \\
\hline Biblioteca & $\mathscr{V}$ & $\mathcal{V}$ & $x$ \\
\hline Cozinha & $\checkmark$ & $\checkmark$ & $\checkmark$ \\
\hline Refeitório & 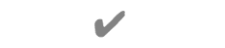 & $\checkmark$ & $\checkmark$ \\
\hline Laboratório de Informática & $x$ & $\checkmark$ & $x$ \\
\hline Laboratório de Ciências & $x$ & $x$ & $x$ \\
\hline Quadra de esportes & $x$ & $x$ & $x$ \\
\hline Sala de aula & $\checkmark$ & $\checkmark$ & $\checkmark$ \\
\hline Sala para leitura & $\checkmark$ & $x$ & $x$ \\
\hline Sala para diretoria & $\checkmark$ & $\checkmark$ & $x$ \\
\hline Sala para professoras(es) & $\checkmark$ & $\checkmark$ & $\checkmark$ \\
\hline Sala para atendimento especializado & $x$ & $x$ & $x$ \\
\hline Banheiros & $\checkmark$ & $\checkmark$ & $\checkmark$ \\
\hline Banheiros adaptados para deficientes & $x$ & $x$ & $x$ \\
\hline Rampas de acessibilidade & $x$ & $x$ & $x$ \\
\hline
\end{tabular}

Fonte: Elaboração nossa. Dados da pesquisa (2015-2019).

Considerando os dados expostos no quadro 2, observamos que as escolas analisadas não disponibilizavam/dispõem de uma infraestrutura básica como prevista no Decreto $\mathrm{n}^{\circ} 7.352 / 2010$. Precisamente, "laboratórios, biblioteca e áreas de lazer e desporto adequados ao projeto políticopedagógico e em conformidade com a realidade local e a diversidade das populações do campo" (BRASIL, 2010). Uma das três escolas não possuía uma biblioteca em sua estrutura, revelando um problema grave, pois o direito dos estudantes de ter acesso aos livros e à oportunidade de uma prática de leitura lhes vem sendo negado. Esse aspecto, sem dúvidas, influencia de maneira negativa no desempenho escolar, haja vista que a falta do hábito de leitura se tornou algo característico do brasileiro. Pois de acordo com Bomeny (2009, p. 22), em um "estudo sobre assiduidade de leitura, feito pela mais antiga revista semanal do mundo, The Economist, o Brasil foi colocado na $27^{a}$ posição entre 30 países e considerado uma 'nação de não-leitores"'.

De acordo com os dados da pesquisa, ressaltamos que as escolas que tinham bibliotecas na sua infraestrutura física, não disponibilizavam livros que abordassem temáticas do campo e/ou livros que fossem atrativos para os estudantes. Esse aspecto torna evidente outro problema, pois além de um espaço físico com limitações, o funcionamento pleno de uma biblioteca está relacionado à disponibilidade de um amplo acervo de livros e atualização de catálogos, de acordo com a proposta pedagógica e interesse das escolas e comunidades do campo (BRASIL, 2010). Para além das bibliotecas, observamos a falta de uma quadra de esportes e equipamentos que contribuam para a prática de exercícios nas três escolas. Logo, esse dado confirma que os estudantes não tinham/têm um espaço adequado para realizarem atividades de Educação Física e de recreação, algo que é fundamental nos primeiros anos escolares, tendo em vista que a prática esportiva:

Possibilita aos alunos uma ampliação da visão sobre a cultura corporal de movimento, e assim, viabiliza a autonomia para o desenvolvimento de uma prática pessoal e a capacidade para interferir na comunidade, seja na manutenção ou na construção de espaços de participação em atividades culturais, como jogos, esportes, lutas, ginásticas e danças, com finalidades de lazer, expressão de sentimentos, afetos e emoções (BRASIL, 1998, p. 15). 
No âmbito da inclusão, os dados revelam que as três escolas não contavam/contam com uma sala de apoio e/ou infraestrutura adequada para atender estudantes deficientes. A arquitetura das escolas não dispõe de rampas de acesso e banheiros acessíveis, o que ressalta que apesar da acessibilidade ser um direito regulamentado pela Norma Brasileira 9050 da Associação Brasileira de Normas Técnicas (ABNT/NBR, 2004) ${ }^{10}$, entre outras legislações, essas exigências não são cumpridas. Desse modo, as evidências empíricas são contundentes em ressaltar que o aspecto legal da acessibilidade configura como um dos maiores desafios das escolas públicas do campo. Como consequência, estudantes deficientes dessas escolas sofrem com o descaso do poder público, no que diz respeito aos seus direitos educativos e cidadania.

A precariedade e ausência de espaços físicos adequados nas escolas do campo traduzem a falta de comprometimento das esferas públicas com a qualidade de ensino e aprendizagem dos estudantes. Isso porque, de acordo com um estudo lançado pela $\mathrm{UNESCO}^{11} \mathrm{em}$ parceria com a Universidade Federal de Minas Gerais (UFMG), a inexistência de espaços pedagógicos como biblioteca, sala de leitura, laboratórios de ciência, etc., apontam desigualdades em relação às escolas urbanas. No referido estudo, constatou-se que "as escolas rurais, com poucos alunos e que atendem aos anos iniciais do ensino fundamental têm sistematicamente escores mais baixos quando comparadas às escolas com maior nível de complexidade" (UNESCO, 2019, p. 68). Essas comparações, embora não considerem a pluralidade de saberes vigentes nas escolas do campo, revelam a falta de efetividade das políticas públicas educativas para o campo. Em outras palavras, o descaso das esferas públicas em relação aos investimentos financeiros voltados à infraestrutura das escolas. Especialmente, os interesses vigentes com propósitos de esvaziamento do campo, as estratégias que o transforma "em um lugar sem pessoas, escolas, plantações, ou seja, sem vida” (RODRIGUES et al., 2017, p. 720).

\section{Serviços de infraestrutura básica: entre a precarização e os serviços mínimos}

Para além da estrutura física, analisamos nesta pesquisa os serviços de infraestrutura básica, indispensáveis para o funcionamento das escolas do campo. Esses serviços são de suma importância, pois garantem o bem-estar dos estudantes e repercutem diretamente na qualidade da educação. De acordo com o artigo $3^{\circ}$ do Decreto $n^{\circ} 7.352 / 2010$, os serviços de infraestrutura se voltam, também, ao objetivo de "III - garantir o fornecimento de energia elétrica, água potável e saneamento básico, bem como outras condições necessárias ao funcionamento das escolas do campo" (BRASIL, 2010). Em outras palavras, as condições essenciais de acesso e permanência de estudantes nas escolas e, portanto, os elementos relacionados à superação dos aspectos históricos de negligenciamento e abandono das escolas do campo. Nesse sentido, os aspectos sobre infraestrutura básica analisados nesta pesquisa podem ser observados no quadro a seguir.

\footnotetext{
10 Disponível em: acessibilidade a edificações, mobiliários, espaços e equipamentos urbanos http://www.aeap.org.br/doc/nbr_9050_2004_acessibilidade.pdf

11 Para ter acesso ao estudo, consulte:

http://www.crianca.mppr.mp.br/arquivos/File/publi/educacao qualidade/qualidade infraestrutura escolas publicas unes co_2019.pdf
} 
Quadro 3. Serviços de Infraestrutura Básica

\begin{tabular}{|l||c||c||c|}
\hline \multicolumn{1}{|c|}{ Aspectos observados } & $\begin{array}{c}\text { Escola Alice do } \\
\text { Amaral Peixoto }\end{array}$ & $\begin{array}{c}\text { Escola João } \\
\text { N eves Brum }\end{array}$ & $\begin{array}{c}\text { Escola } \\
\text { Anacleto } \\
\text { Eccard Júnior }\end{array}$ \\
\hline Alimentação escolar & $\checkmark$ & $\checkmark$ & $\checkmark$ \\
\hline Água potável & $\checkmark$ & $\checkmark$ & $\checkmark$ \\
\hline Saneamento básico & $\checkmark$ & $\checkmark$ & $\checkmark$ \\
\hline Energia elétrica & $\checkmark$ & $\checkmark$ & $\checkmark$ \\
\hline Rede de telefone & $\checkmark$ & $x$ & $x$ \\
\hline Acesso à internet & $\checkmark$ & $x$ & $\checkmark$ \\
\hline Transporte escolar & $\checkmark$ & $x$ & $x$ \\
\hline
\end{tabular}

Fonte: Elaboração nossa. Dados da pesquisa (2015-2019).

Entre os dados relacionados aos serviços de infraestrutura, um aspecto apresenta-se relevante; ou seja, a constatação da participação dos agricultores da região no fornecimento da alimentação para essas escolas do campo. Isso é possível mediante ao Programa Nacional de Alimentação Escolar (PNAE), implementado pela Lei no 11.947 de 16 de junho de 2009. O artigo 14 dessa lei enfatiza que do total de recursos financeiros repassados pelo Fundo Nacional de Desenvolvimento da Educação (FNDE), no âmbito do PNAE, "no mínimo 30\% (trinta por cento) deverão ser utilizados na aquisição de gêneros alimentícios diretamente da agricultura familiar e do empreendedor familiar rural ou de suas organizações" (BRASIL, 2009). Ademais, o referido artigo destaca a necessidade de priorização, na compra de alimentação escolar, gêneros alimentícios oriundos de "assentamentos da reforma agrária, as comunidades tradicionais indígenas e comunidades quilombolas" (BRASIL, 2009).

Identificar, nas três escolas pesquisadas, a concretização do acesso à alimentação escolar, com participação da agricultura familiar, é algo positivo. Sobretudo se considerarmos que a alimentação escolar, em alguns contextos e realidades sociais brasileiras, "muitas vezes, torna-se a principal refeição dessas crianças. Estudos recentes indicam que, para 50\% dos alunos da região Nordeste, a merenda escolar é considerada a principal refeição do dia" (CAVALCANTI et al., 2009, p. 1). Contraditoriamente, os dados relacionados ao acesso à internet ressaltam as faces da precarização, já que esse serviço era/é bem específico, a partir da realidade de cada uma das três escolas. Na Escola Alice do Amaral Peixoto, por exemplo, tem acesso à internet, porém não há um laboratório de informática para os estudantes. Essa ausência reduz as oportunidades de inclusão digital dentro da estrutura da escola e, assim, contraria o que preconiza o Decreto $\mathrm{n}^{\circ} 7.352 / 2010$, especialmente quando o referido decreto enfatiza que "caberá à União, em colaboração com as demais esferas públicas, criar e implementar mecanismos que garantam o desenvolvimento da educação do campo" (BRASIL, 2010).

O Decreto $\mathrm{n}^{\circ} 7.352 / 2010$ estabelece que a função do poder público consiste em “contribuir para a inclusão digital por meio da ampliação do acesso a computadores, à conexão à rede mundial de computadores e a outras tecnologias digitais, beneficiando a comunidade escolar e a população próxima às escolas do campo" (BRASIL, 2010). A ausência de condições que promovam a inclusão digital estende-se as outras duas escolas - João Neves Brum e Anacleto Eccard Júnior - as quais tinham laboratório de informática e notebooks à disposição, porém não havia acesso à internet. Sobre esse tema, Belusso e Pontarolo (2017, p. 4) destacam que, segundo o Censo Escolar de 2016, "apenas 9,9\% das 76.229 escolas brasileiras existentes no campo possuem acesso à Internet. Em áreas urbanas, o número chega a 85\% e vem crescendo".

Os dados apresentados na pesquisa de Belusso e Pontarolo (2017) tornam evidentes as disparidades do acesso digital entre o território urbano e o rural e, portanto, as desigualdades mediadas pela ineficácia na implementação das políticas públicas voltadas à Educação do Campo. Com base 
nesses percentuais, os autores sinalizam que "na sociedade da tecnologia torna-se um direito o acesso à informatização, a inclusão digital e as inúmeras possibilidades que se abrem com o acesso à rede mundial de computadores" (BELUSSO; PONTAROLO, 2017, p. 5). Logo, esse direito deve contemplar as/os estudantes das escolas do campo, uma vez que "o acesso à Internet abre para essas comunidades a possibilidade de criação de uma identidade própria nesse mundo virtual. Além de consumir conteúdos, os moradores de zonas rurais passam a ter a possibilidade de produzir conteúdos sobre sua realidade e cultura" (BELUSSO; PONTAROLO, 2017, p. 6).

Para além das ausências sinalizadas, os dados da pesquisa revelam que o transporte escolar, na realidade pesquisada, apresentou-se como um dos maiores problemas enfrentados por todas as três escolas. Apesar de duas escolas disporem de transporte regular, durante os meses de chuva as/os estudantes da Escola Alice do Amaral Peixoto e Escola Anacleto Eccard Júnior, eram impossibilitados de irem às aulas, uma vez que as estradas ficavam inacessíveis, o que impedia a circulação de veículos. Paralelo a isso, na Escola João Neves Brum, além das estradas de difícil acesso, o funcionamento do transporte escolar foi interrompido pela prefeitura sem maiores esclarecimentos à comunidade escolar, dificultando o acesso de muitos estudantes à escola. Tal ação, atenta contra os direitos educativos previstos na Lei $n^{\circ} 9.394 / 96$, art. 4, quando estabelece que o dever do Estado "com a educação escolar pública será efetivado mediante a garantia de: [...] atendimento ao educando, no ensino fundamental público, por meio de programas suplementares de material didático-escolar, transporte, alimentação e assistência à saúde" (BRASIL, 1996).

Os resultados indicam que a falta de transporte escolar favorece a interrupção dos conteúdos trabalhados em sala de aula. Ao mesmo tempo contraria as disposições do Decreto $\mathrm{n}^{\circ}$ 7.352/2010, quando enfatiza a necessidade da "oferta de transporte escolar, respeitando as especificidades geográficas, culturais e sociais, bem como os limites de idade e etapas escolares" (BRASIL, 2010). Para Freitas (2011, p. 6), as "rupturas no processo de ensino e aprendizagem prejudicam o desenvolvimento das atividades de ensino", as quais "requer ações contínuas para que haja absorção significativa dos conteúdos aplicados pelos docentes" (FREITAS, 2011, p. 6). A logística do transporte escolar revelou-se um problema, também, na escola Anacleto Eccard Júnior, em função das estradas de difícil acesso. Nessa escola, para fazer uso do transporte escolar, as/os estudantes precisavam acordar aproximadamente às $5 \mathrm{~h}$ da manhã e retornavam tarde para suas casas. Essas evidências empíricas, associadas às conclusões de outros estudos, indicam que, lamentavelmente, essa realidade é compartilhada por outras escolas do campo (RODRIGUES et al., 2017; SCHWENDLER, 2005). Nessa perspectiva, os resultados encontrados por Schwendler (2005, p. 53) enfatizam que:

Devido às distâncias entre os moradores e as próprias comunidades onde passa o transporte escolar, os educandos são obrigados a levantar muitas vezes de madrugada e/ou ficarem horas no trajeto entre sua casa e a escola. Assim, ficam à margem do cotidiano da vida e dos valores do campo. Quando educandos são retirados do seu contexto para estudar (por meio da nuclearização na cidade), são afastados de suas raízes culturais, de sua identidade.

Os dados da pesquisa indicam que o poder público vem utilizando diferentes estratégias de estrangulamento, delineadas a partir da precarização. Isto é, inicialmente, a qualidade da infraestrutura das escolas é comprometida, com ausência de espaços educativos e, posteriormente, com a falta de manutenção e transporte escolar. Todos esses fatores são criados com a intenção de justificar processos de nucleação e fechamento das escolas. Porém, é urgente denunciarmos que o fechamento das escolas do campo "é um crime contra a nação brasileira que continua e precisa ser interrompido e revertido" (TAFFAREL; MUNARIM, 2015, p. 47). Na tentativa de frear as práticas de fechamento das escolas do campo, a Lei $\mathrm{n}^{\circ} 12.960$ de 27 de março de 2014, alterou o artigo $28^{\circ}$ da Lei $\mathrm{n}^{\circ}$ 9.394/96. Tal artigo enfatiza que o fechamento de escolas do campo - incluindo as indígenas e quilombolas - "será precedido de manifestação do órgão normativo do respectivo sistema de ensino, que considerará a justificativa apresentada pela Secretaria de Educação a análise do diagnóstico do impacto da ação e a manifestação da comunidade escolar" (BRASIL, 2014).

\section{Equipamentos e funcionamento das escolas: precarização enquanto justificativa para fechamento}


Nesta parte da pesquisa, resgatamos os dados relacionados aos equipamentos disponíveis nas escolas do campo, considerando que esses recursos técnicos interferem, também, nas dinâmicas de funcionamento da escola e influenciam no processo de ensino e aprendizagem. A pertinência dessa questão está associada ao entendimento de que os "materiais e equipamentos, alguns mais prosaicos, como as carteiras da sala de aula e outros usados em nossas escolas, dependendo de sua concepção, de suas especificações, podem ser e podem não ser didáticos, podem ser ou não ser educativos" (FREITAS, 2007, p. 12). Logo, sua relevância é totalmente percebida no dia a dia, considerando que esses equipamentos fazem parte da manutenção de um espaço escolar, além da sua contribuição para a criação de um ambiente adequado ao desenvolvimento de habilidades e competências, sejam elas cognitivas, sociais, políticas ou ambientais. Os recursos/equipamentos analisados nesta pesquisa, conforme quadro abaixo, fazem parte das especificações previstas no manual Mobiliário e Equipamento Escolar, estabelecido pelo FNDE ${ }^{12}$.

Quadro 4-Equipamentos disponíveis nas escolas

\begin{tabular}{|l|c||c||c|}
\hline \multicolumn{1}{|c|}{ Aspectos observados } & $\begin{array}{c}\text { Escola Alice do } \\
\text { Amaral Peixoto }\end{array}$ & $\begin{array}{c}\text { Escola João } \\
\text { N eves Brum }\end{array}$ & $\begin{array}{c}\text { Escola } \\
\text { Anacleto } \\
\text { Eccard Júnior }\end{array}$ \\
\hline Aparelho de DVD & $\checkmark$ & $x$ & $x$ \\
\hline Computadores & $x$ & $\checkmark$ & $x$ \\
\hline Impressora & $\checkmark$ & $\checkmark$ & $x$ \\
\hline Máquina copiadora & $\checkmark$ & $x$ & $x$ \\
\hline Projetor & $\checkmark$ & $x$ & $x$ \\
\hline Televisão & $\checkmark$ & $x$ & $x$ \\
\hline Antena de TV & $x$ & $x$ & $x$ \\
\hline
\end{tabular}

Fonte: Elaboração nossa. Dados da pesquisa (2015-2019).

A partir dos dados apresentados, podemos observar que a escola Alice do Amaral Peixoto se destaca no quesito de equipamentos disponíveis, enquanto a escola João Neves Brum e a escola Anacleto Eccard Júnior não disponibilizavam, em grande parte, dos equipamentos elencados. Com essas evidências, podemos constatar o descaso com essas escolas do campo e, por conseguinte, o quanto suas infraestruturas estavam/estão comprometidas por falta de manutenção e investimentos do poder público. Sobre esse tema, Luther e Gehardt (2018, p. 299) sinalizam que o "descrédito no ensino formal e público se faz pela precarização da infraestrutura de cada sala de aula". Ainda, de acordo com os autores, "se um estudante que não tem luz, água, alimento ou mesa, cadeira materiais escolares próprios para produzir e reproduzir seus conhecimentos, como repensar as práticas pedagógicas?" (LUTHER; GEHARDT, 2018, p. 299). Pelas evidências práticas e teóricas, entendemos que infraestrutura é um dos fatores determinantes para a qualidade da aprendizagem e para $\mathrm{O}$ desenvolvimento da Educação do Campo.

Diante do exposto, torna-se evidente que a infraestrutura das escolas do campo do Noroeste Fluminense, microrregião de Santo Antônio de Pádua, e sua precarização espelham uma realidade nacional. De acordo com os dados da pesquisa e com as informações divulgadas no site Escolas.inf.br (2015), as escolas mais precarizadas, mesmo aquelas que não configuravam como objeto de interesse principal nesta pesquisa, não foram encontradas nos dados oficiais do INPE. Por sua vez,

12 Para ter acesso ao manual de Mobiliário e Equipamento Escolar, consulte: https://www.fnde.gov.br/index.php/programas/proinfancia/eixos-de-atuacao/mobiliario-e-equipamentos 
nas três escolas pesquisadas, os dados expostos nos quadros 2, 3 e 4 sinalizam que todos os aspectos que foram precarizados tornam-se pretextos para justificar o fechamento das escolas, os quais, por meio de argumentos com viés economicistas, potencializam os discursos de negação do direto à Educação do Campo. Para Schmitz e Castanha (2017, p. 46), os argumentos são quase sempre os mesmos: "poucos alunos sendo atendidos e isso torna o custo por aluno alto demais, fica inviável manter a escola; é preciso remover esses alunos e colocá-los em uma escola maior". Para convencer a comunidade escolar, o fechamento das escolas do campo é justificado "dizendo que tudo isso será melhor para os educandos, já que terão acesso a uma infraestrutura de maior e melhor qualidade, e desse modo, poderão aprender mais, sem se levar em conta os aspectos culturais e sociais presentes nessa mudança" (SCHMITZ; CASTANHA, 2017, p. 46).

Com base nos dados da pesquisa, entendemos que o projeto de esvaziamento do campo e desterritorialização das populações do campo opera a partir de diferentes lógicas, sobretudo no âmbito da contraditória das políticas educacionais e da ausência, intencional, do Estado. Atualmente, na cidade de Santo Antônio de Pádua, percebe-se o movimento do êxodo rural, pois durante as vivências nas escolas do campo, moradores das comunidades locais relataram que estão indo morar na cidade devido à falta de infraestrutura no campo. Tendo em vista que não há investimentos por parte do poder público nas zonas rurais da região, a falta de infraestrutura para as comunidades se apresenta nas seguintes ausências: hospitais e postos de saúde, iluminação pública, estradas de difícil acesso, entre outras (NEVES et al., 2019). Os dados revelam que o desemprego tem afetado, também, a vida das populações campesinas, as quais, em alguns casos com pouca instrução escolar, pensam em mudar para a cidade, com o objetivo de melhores oportunidades de vida. Tal como destaca Arroyo (2007, p. 159), "as consequências dessa inspiração no paradigma urbano são marcantes na secundarização do campo e na falta de políticas para o campo em todas as áreas públicas, saúde e educação de maneira particular. O campo é visto como uma extensão, como um quintal da cidade".

Com essa leitura da realidade, Arroyo (2007, p. 159) sintetiza: "os profissionais urbanos, médicos, enfermeiras, professores estenderão seus serviços ao campo. Serviços adaptados, precarizados, no posto médico ou na escolinha pobres, com recursos pobres". Nessa precarização, os profissionais urbanos levam seus serviços ao campo, contudo, "sobretudo nos anos iniciais, sem vínculos culturais com o campo, sem permanência e residência junto aos povos do campo" (ARROYO, 2007, p. 159). Dessa forma, a resistência contra o fechamento das escolas do campo se faz cada dia mais necessária, pois vivenciar as diferentes realidades do campo, por meio desta pesquisa, permitiu-nos fazer outras leituras das diferentes lógicas que operam de forma individual ou sincronizada. Concretamente, a expansão de diferentes interesses econômicos no campo, especialmente no que diz respeito a desenraizar as populações do campo, de modo que estas percam as suas Terras e, com elas, a sua identidade.

\section{CONSIDERAÇÕES FINAIS}

Os elementos empíricos desta pesquisa sinalizam que a precarização da infraestrutura das escolas do campo vai desde uma estrutura física comprometida e se estende à ausência de serviços básicos, como a falta de transporte escolar e o acesso limitado à internet. Diante dessa realidade, a pesquisa destaca que a precariedade da infraestrutura das escolas do campo decorre da ineficiência e descaso, intencional, do poder público em garantir a efetividade da política de Educação do Campo. Na cidade de Santo Antônio de Pádua, as esferas públicas recorreram ao argumento da inviabilidade econômica para reestruturar as escolas, com a finalidade de justificar o fechamento criminoso de escolas do campo. Logo, os dados indicam que o projeto de fechamento de escolas do campo atua no sentido de resguardar as concepções hegemônicas de poder e saber, que funcionam, exclusivamente, em prol de atender aos interesses do capital. No centro dessas concepções persistem as tensões políticas, econômicas e ambientais atuais que caracterizam a luta pela Terra e, portanto, as estratégias de esvaziamento do campo. Sobretudo, quando duas escolas do campo foram fechadas na cidade de Santo Antônio de Pádua e cinco escolas na cidade de Aperibé. Ademais, quando 14 escolas, das demais 
cidades da microrregião de Santo Antônio de Pádua, não constam nos dados oficiais do INEP, nos últimos anos.

Com exceção das duas escolas da cidade de Santo Antônio de Pádua, as informações da pesquisa não nos permitem elencar, com precisão, os motivos reais que levaram à ausência de informações de 19 escolas nos dados do INEP. Contudo, as evidências empíricas nos permite conjecturar que o projeto de esvaziamento do campo é viabilizado de diferentes formas, entre elas a precarização das escolas do campo, enquanto estratégia sutil para justificar o fechamento. Por conseguinte, tal projeto coloca em prática a proposta de educação urbana, a qual nega as lutas, as territorialidades, as identidades, os modos de vida e os saberes das populações campesinas. Pois, mesmo em contextos de ausência completa das agências públicas responsáveis por assegurar direitos fundamentais, o argumento da precarização das escolas e da qualidade do ensino revelou-se como o fator determinante para as comunidades justificarem o êxodo rural. Nesse sentido, a sutileza anteriormente mencionada persiste, também, nas produções científicas sobre o tema, uma vez que as pesquisas voltadas à infraestrutura das escolas do campo mostraram-se incipientes na área da educação. Os trabalhos publicados sobre o tema são pontuais, o que denota, por um lado, a possibilidade desse campo de pesquisa se encontrar em fase inicial de expansão. Por outro, que a temática da infraestrutura das escolas do campo, enquanto variável e/ou categoria de análise, não tem recebido a devida atenção em um panorama mais amplo de compreensão do fenômeno de fechamento de escolas do campo.

Com os elementos apresentados, destacamos que o campo, enquanto território multidimensional, continua sendo vítima de um processo de produção de desigualdades socioeconômicas e étnico-raciais, oriundas desde a formação do Brasil. As populações campesinas, no contexto estudado, lidam, diariamente, com a ausência e traição do Estado e, por conseguinte, com seus direitos fundamentais violados. Essa violação se manifesta por meio da precariedade de condições básicas de vida. Precisamente, devido à falta de acesso à educação, saúde, iluminação pública, estradas com qualidade, entre outros. Esses fatores nos leva a considerar que a Educação do Campo se insere no espaço de lutas e de tensões políticas voltadas a provocar rupturas no modelo hegemônico de educação. Contudo, tais lutas são assimétricas no contexto político nacional, no qual a Lei $\mathrm{n}^{\circ}$ 12.960/2014 não conseguiu frear o projeto de fechamento de escolas do campo, uma vez que o artigo $28^{\circ}$ da Lei no 9.394/96 não foi aplicado no fechamento das escolas Joao Neves Brum e Anacleto Eccard Júnior; bem como, nas três tentativas de fechamento da Escola Alice do Amaral Peixoto. Com isso, entendemos que tal projeto é viabilizado por meio de estratégias sutis de estrangulamento das condições essenciais de acesso aos direitos fundamentais e, portanto, a inviabilidade de permanência das comunidades em seus territórios.

\section{REFERÊNCIAS}

ABNT. Associação Brasileira de Normas Técnicas. NBR 9050: Acessibilidade a edificações, mobiliário, espaços e equipamentos urbanos. Rio de Janeiro, 2004. Disponível em: < http://www.aeap.org.br/doc/nbr 9050 2004 acessibilidade.pdf> Acesso em: 10 nov. 2019

ACSELRAD, Henri. Disputas cognitivas e exercício da capacidade crítica: o caso dos conflitos ambientais no Brasil. Sociologias, v. 16, n. 35, 2014, p. 84-105.

ANDRADE, Francisca Marli Rodrigues; NOGUEIRA, Letícia Pereira Mendes; RODRIGUES; Marcela Pereira Mendes. Tempo Comunidade - espaçotempo potencializador de experiências na formação de educadores do campo. In: COSTA, Alvaro Daniel (Org.). Cultura, cidadania e políticas públicas 2. Ponta Grossa (PR): Atena Editora, 2019, p. 154-163, 2019 a.

ANDRADE, Francisca Marli Rodrigues; NOGUEIRA, Letícia Pereira Mendes; NEVES, Lucas Couto; RODRIGUES, Marcela Pereira Mendes. Educação do Campo em giro decolonial: a experiência do Tempo Comunidade na Universidade Federal Fluminense (UFF). Revista Brasileira de Educação do Campo, Tocantinópolis, v. 4, e7178, 2019b, p. 1-30. 
ARROYO, Miguel Gonzalez. Políticas de formação de educadores(as)do campo. Cad. Cedes, Campinas, vol. 27, n. 72, p. 157-176, maio/ago. 2007.

ARROYO, Miguel Gonzalez. Formação de Educadores do Campo. In: CALDART, Roseli Salete et al. (Org.). Dicionário da Educação do Campo. Rio de Janeiro, São Paulo: Escola politécnica de Saúde Joaquim Venâncio, Expressão Popular, 2012, p. 359-365.

BANIWA, Gersem. Educação escolar indígena no século XXI: encantos e desencantos. Rio de Janeiro: Mórula, Laced, 2019.

BELUSSO, Andreia; PONTAROLO, Edilson. Uma reflexão sobre tecnologia digital nas escolas do campo como possibilidade para o desenvolvimento dos territórios camponeses. In: VIII Seminário Internacional sobre Desenvolvimento Regional, 2017, Santa Cruz do Sul. Anais..., p. 1-12, 2017.

BOMENY, Helena. Leitura no Brasil, leitura do Brasil. Sociologia, problemas e práticas, n. 60, p. 11-32, 2009.

BRASIL. Ministério de Educação. LDB - Lei n⿳0 9394/96, de 20 de dezembro de 1996. Estabelece as diretrizes e bases da Educação Nacional. Brasília: MEC, 1996. Disponível em:

< http://www.planalto.gov.br/ccivil 03/leis/19394.htm > Acesso em: 10 nov. 2019

BRASIL. Secretaria de Educação Fundamental. Parâmetros curriculares nacionais: Educação

Física. Brasília: MEC/SEF, 1998. 114 p. Disponível em:

< http://portal.mec.gov.br/seb/arquivos/pdf/fisica.pdf> Acesso em: 05 nov. 2019.

BRASIL, CNE. Resolução CNE/CEB 1/2002. Diretrizes Operacionais para Educação Básica nas Escolas do Campo. Diário Oficial da União, Brasília, 9 de abril de 2002. Seção 1, p. 32. Disponível $\mathrm{em}: \quad<$ http://portal.mec.gov.br/index.php?option $=$ com docman\&view $=$ download\&alias $=13800_{-}$ rceb001-02-pdf\&Itemid $=30192>$ Acesso em: 09 nov. 2019

BRASIL. Ministério da Educação. Secretaria de Educação Básica. Parâmetros básicos de infraestrutura para instituições de educação infantil. Brasília: MEC, SEB, 2006. Disponível em:

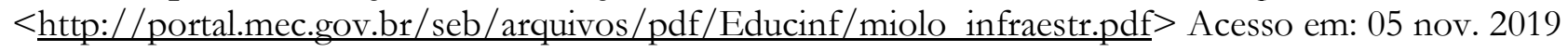

BRASIL. Lei ${ }^{\circ} \mathbf{1 1 . 9 4 7}$ de 16 de junho de 2009. Dispõe sobre o atendimento da alimentação escolar e do Programa Dinheiro Direto na Escola aos alunos da educação básica. Diário Oficial da União 2009. < http://www.planalto.gov.br/ccivil 03/ Ato2007-2010/2009/Lei/L11947.htm> Acesso em: 12. nov. 2019

BRASIL. Decreto $\mathbf{n}^{\mathbf{0}} \mathbf{7 . 3 5 2}$, de 4 de novembro de 2010. Disponível em: < http://www.planalto.gov.br/ccivil 03/ ato2007-2010/2010/decreto/d7352.htm>. Acesso em: 10 nov. 2019.

BRASIL. Presidência da República. Lei n. 12.960, de 27 de março de 2014. Disponível em: <http://www.planalto.gov.br/ccivil 03/ Ato2011-2014/2014/Lei/L12960.htm> Acesso em: 10 nov. 2019 .

CALDART, Roseli Salete. Educação do campo. In: CALDART, Roseli Salete et al. (Org.). Dicionário da Educação do Campo. Rio de Janeiro, São Paulo: Escola politécnica de Saúde Joaquim Venâncio, Expressão Popular, 2012, p. 257-264.

CASSIN, Marcos; BEZERRA, Luiz. Número de escolas no campo diminui drasticamente no Brasil. 2017. Disponível em: <http://www.fai.ufscar.br/noticia/numero-de-escolas-no-campodiminui-drasticamente-no-brasil.html>. Acesso em: 09 nov. 2019.

CAVALCANTI, Amanda da Fonseca.; SILVA, Celiane Gomes Maia da; SILVA, Maria Zenia Tavares da. Merenda escolar: uma questão de saúde e cidadania. Jornada de Ensino, Pesquisa e Extensão da UFRP, v. 9, 2009, p. 1-3. Disponível em:

< http://www.eventosufrpe.com.br/jepex2009/cd/resumos/R0077-1.pdf> Acesso em: 13 nov. 2019.

COELHO, Leila Rocha Sarmento. A função social da escola na Educação do Campo. Revista

Lugares de Educação, Bananeiras/PB, v. 1, n. 2, p. 136-149, jul.-dez. 2011. 
ESCOLAS.INF.BR. - Informações das escolas no Brasil. Escolas públicas e particulares nas cidades do estado de RJ. Disponível em: <http://www.escolas.inf.br/estado/rj> Acesso em: 17 maio. 2020.

FREITAS, Dulceli Pierin de. O transporte Escolar e sua Influência no Aprendizado do Aluno do Campo. 11 p. Monografia (Especialização) - Curso de Especialização em Educação do Campo - Ead, Universidade Federal do Paraná, Paraná, 2011. Disponível em:

<https://acervodigital.ufpr.br/bitstream/handle/1884/38494/R\%20-\%20E\%20-

$\% 20$ DULCELI $\% 20$ PIERIN $\% 20 D E \% 20 F R E I T A S$.pdf?sequence=1\&isAllowed $=\mathrm{y}>$. Acesso em: 10 nov. 2019.

FREITAS, Olga. Equipamentos e materiais didáticos. 1. ed. Brasília: Universidade de Brasília, 2007.

GIL, Antônio Carlos. Como elaborar projetos de pesquisa. 5. ed. São Paulo: Atlas, 2010.

IBGE - Instituto Brasileiro de Geografia e Estatística. Santo Antônio de Pádua - IBGE Cidades, 2010 .

INEP. Instituto Nacional de Estudos e Pesquisas Educacionais Anísio Teixeira. Panorama da Educação no Campo. Brasília: Instituto Nacional de Estudos e Pesquisas Educacionais Anísio Teixeira, 2007. Disponível em:

$<$ http://inep.gov.br/documents/186968/484154/Panorama+da+Educa\%C3\%A7\%C3\%A3o+do+Ca mpo/5b9c2ed7-208b-48ff-a803-cd3851c5c6c9?version=1.2> Acesso em: 12 nov. 2019.

INEP. Instituto Nacional de Estudos e Pesquisas Educacionais Anísio Teixeira. Índice de

Desenvolvimento da Educação Básica (Ideb). Brasília, 2020. Disponível em:

<http://idebescola.inep.gov.br/ideb/consulta-publica> Acesso em: 13 de maio. 2020.

KOWALTOWSKI, Doris Catharine et al. Reflexão sobre metodologias de projeto arquitetônico.

Ambiente Construído, v. 6, n. 2, p. 7-19, 2006. Disponível em:

< https://seer.ufrgs.br/ambienteconstruido/article/view/3683> Acesso em: 11 nov. 2019.

LUTHER, Alessandra; GERHARDT, Tatiana Engel. Educação obrigatória, êxodo rural e fechamento das escolas do campo no brasil. Revista Saberes da Amazônia, v. 3, n. 07, p. 281-310, 2018.

Disponível em: < https://www.fcr.edu.br/ojs/index.php/saberesamazonia/article/view/292> Acesso em: 12 nov. 2019

MINAYO, Maria Cecília de Souza. (Org.). Pesquisa social: teoria, método e criatividade. 33. ed. Petrópolis, RJ: Vozes, 2013.

MOLINA, Mônica Castagna; SÁ, Laís Mourão. Escola do Campo. In: CALDART, Roseli Salete et al. (Org.). Dicionário da Educação do Campo. Rio de Janeiro, São Paulo: Escola politécnica de Saúde Joaquim Venâncio, Expressão Popular, 2012, p. 324-330.

NEVES, Lucas do Couto; SANTOS, Pablo Peixoto de Jesus; CORRÊA, Bruno de Oliveira; ANDRADE, Francisca Marli Rodrigues de. Memória social e resistência: organização comunitária contra o fechamento da escola Alice do Amaral Peixoto. In: COSTA, Álvaro Daniel (org.). Cultura, cidadania e políticas públicas. v. 4. Ponta Grossa (PR): Atena Editora, 2019, p. 130-137.

PIOVESAN, Armando; TEMPORINI, Edméa Rita. Pesquisa exploratória: procedimento metodológico para o estudo de fatores humanos no campo da saúde pública. Revista de Saúde Pública, v. 29, n. 4, São Paulo, p. 318-325, 1995. Disponível em:

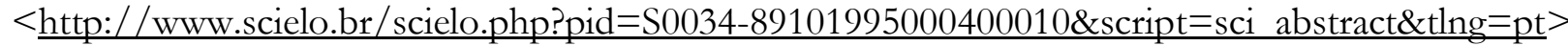
Acesso em: 05 nov. 2019

RIBEIRO, Marlene. Movimento Camponês, Trabalho, Educação. Liberdade, autonomia, emancipação como princípios/fins da formação humana. São Paulo, Expressão Popular, 2013.

RODRIGUES, Ana Cláudia da Silva et al. Nucleação de Escolas no Campo: conflitos entre formação e desenraizamento. Educação \& Realidade, v. 42, n. 2, p. 707-728, 2017. Disponível em: 


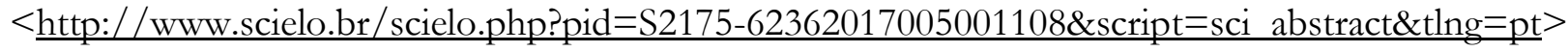
Acesso em: 09 nov. 2019.

SCHMITZ, Micheli Tassiana; CASTANHA, André Paulo. Fechamento de escolas do campo: o caso da Escola Estadual do Campo Canoas - Cruzeiro do Iguaçu - PR. Imagens da Educação, v. 7, n. 1, p. 38-48, 2017. Disponível em: < http://periodicos.uem.br/ojs/index.php/ImagensEduc/article/view/32286 > Acesso em: 15 nov. 2019.

SCHWENDLER, Sônia Fátima. Principais problemas e desafios da educação do campo no Brasil e no Paraná. In: Caderno temático da educação do campo. Secretaria de Estado da Educação do Paraná. Curitiba: SEED, 2005. Disponível em: <

http://www.educadores.diaadia.pr.gov.br/arquivos/File/cadernos tematicos/caderno tematico camp o01.pdf > Acesso em: 12 nov. 2019.

SOARES NETO, Joaquim José et al. A infraestrutura das escolas públicas brasileiras de pequeno porte. Revista do Serviço Público, Brasília, v. 64, n. 3, p. 377-391, jul./ set. 2013. Disponível em: <https://revista.enap.gov.br/index.php/RSP/article/view/129> Acesso em: 10 nov. 2019.

TAFFAREL, Celi Zulke; MUNARIM, Antonio. Pátria educadora e fechamento de escolas do campo: o crime continua. Revista Pedagógica, v. 17, n. 35, p. 41-51, 2015. Disponível em:

$<$ https://bell.unochapeco.edu.br/revistas/index.php/pedagogica/article/view/3053> Acesso em: 06 nov. 2019.

UNESCO. Qualidade da infraestrutura das escolas públicas do ensino fundamental no Brasil. Brasilia: UNESCO, 2019.

WHYTE, William Foote. Sociedade de esquina: a estrutura social de uma área urbana pobre e degradada. Trad. Maria Lúcia de Oliveira. Rio de Janeiro: Jorge Zahar, 2005. 